\title{
A POLÍTICA DE COTAS ÉTNICO-RACIAIS PARA CONCURSOS PÚBLICOS DE ENSINO SUPERIOR
}

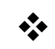 \\ Grace Vieira Martinez Pena \\ Universidade de Santa Cruz do Sul-UNISC-Brasil \\ Dra. Denise Bittencourt Friedrich \\ Orientadora \\ Universidade de Santa Cruz do Sul-UNISC-Brasil \\ Mozart Linhares da Silva \\ Coorientador \\ Universidade de Santa Cruz do Sul - UNISC - Brasil
}

\section{Resumo}

A situação problemática que instigou a presente pesquisa é se os fundamentos da Política Pública de inclusão étnico-racial, através da reserva de cotas em concursos públicos de nível superior, instituídas pela lei 12.990/2014, se sustentam diante do princípio igualdade material, considerando que já existe uma política de inclusão nos cursos superiores das universidades públicas para este grupo? Para responder esta indagação, o método de abordagem foi o hipotético-dedutivo, haja visto que a partir do problema levantado algumas hipóteses podem ser arguidas, as quais serão, ao longo da pesquisa, refutadas ou confirmadas. Quanto à técnica de pesquisa empregou-se a consulta de bibliografia, de periódicos e de acervos jurisprudenciais. Assim, partindo-se do pressuposto de que a já existente Política Pública de cotas étnico-raciais para inclusão nos cursos de ensino superior implementada pela lei $12.711 / 2012$, se dispõe exatamente em viabilizar o requisito mínimo para aqueles que pretendem concorrer às vagas de nível superior de ensino dispostas pela Administração Pública, pode-se afirmar que existe uma relação de bis in idem entre as leis em comento. No entanto, apesar dessa constatação, resta compreensível e aceitável a aplicação da lei 12.990/2014 devido à obrigação do Estado, inclusive perante o cenário internacional, em promover a plenitude da igualdade material, como também, conforme o argumento da Ordem dos Advogados do Brasil, na promoção da estabilidade sociocultural in loco, proporcionando o sentimento de pertença nas gerações vindouras.

Palavras-chave: Concursos públicos; cotas; Igualdade material; política pública.

\section{Introdução}

Inicialmente, e de forma sintetizada, o presente estudo faz uma referência às Políticas Públicas tendo em vista o fato de o tema delineado repousar na aplicação fática dessas políticas. Assim, expõe a importância da participação de todos os interessados nas mais diversas demandas, incluindo o Estado Administrador e os administrados. Considerando, ainda, o fato do tema em comento estar intimamente ligado às questões étnicos-raciais, um breve histórico da população negra do Brasil se fez necessário desde a Lei Áurea, e do fato 
desta não ter sido associada a nenhum processo fático de integração além da política de branqueamento da sociedade brasileira, chegando até aos dias atuais e esclarecendo o motivo que culminou na impossibilidade de autossustentação e de ascensão social desses indivíduos, o que leva à razão da demanda pela inclusão social dos afrodescendentes ter-se tornado cada vez mais emergente e debatida em todos os seguimentos de estudo dos fenômenos sociais de modo geral, dos quais se destaca a ampla seara do Direito, especialmente na Constituição Federal de 1988 que propiciou a abertura para a discussão sobre as políticas públicas e sociais no Brasil, as quais destinam recursos em benefício de grupos vitimados pelas mais diversas formas de exclusão, como as étnicas-raciais. Dessa forma, o tema política de cotas étnicoraciais para concursos públicos de ensino superior prevista pela lei 12.990/2014 pode ser entendida como forma de promoção da justiça social assim como a lei 12.711/2012 somada à outras políticas sociais, são consideradas um veículo para a ascenção social e materialização da dignidade da pessoa humana.

Ainda, sendo os concursos públicos procedimentos administrativos próprios do Poder Público, portanto, matéria do Direito Administrativo, seguem normas obrigatórias e princípios norteadores congruentes à Constituição objetivando um gerenciamento adequado das atividades estatais, ou seja, de interesse comum.

A problemática deste estudo, em suma, repousa na questão de os fundamentos da Política Pública de inclusão étnico-racial, através da reserva de cotas em concursos públicos de nível superior - lei 12.990/2014 - se sustentarem ou não diante do princípio igualdade material, haja vista a já existente política de inclusão nos cursos superiores das universidades públicas instituída pela lei 12.711/2012. Noutras palavras, o que se questiona aqui são os postulados teóricos e jurídicos das políticas públicas afirmativas de inclusão do negro no Brasil e a (in)existência de bis in idem da lei 12.990/2014 frente a lei 12.711/2012.

Não obstante às leis em comento, os conceitos doutrinários, sociológicos e jurisprudenciais, além de dados estatísticos produzidos por órgãos e institutos de pesquisa, auxiliaram o entendimento da questão proposta, de forma a trazer o presente estudo o mais próximo possível do fiel da balança.

Contudo, vale ressaltar, que este estudo não possui o ânimo de esgotar o tema, já que trata de múltiplos interesses, todavia, deve ser considerado como uma forma de debate sobre a problemática cotas versus direito material e a observância do interesse público.

\section{As políticas de inclusão antes e depois da Constituição Federal de 1988}

A Constituição Federal de 1988 é considerada um marco jurídico ímpar e, desde seu 
preâmbulo ela ressalta a importância da sociedade no processo da democracia e dos direitos sociais. Ela não só oportunizou a discussão sobre as políticas públicas e sociais no Brasil, como também possibilitou que tais políticas fossem aplicadas, promovendo o acesso de grupos desfavorecidos à educação, saúde, emprego, bens materiais ou ao reconhecimento cultural, além do acesso à proteção da dignidade da pessoa humana, repudiando e punindo a manifestações racistas e discriminatórias.

Políticas públicas, então, são instituídas pelo Estado através de ações jurídicas, administrativas e sociais, baseadas na proporcionalidade e na reserva do possível ${ }^{1}$, de acordo com as demandas impulsionadas pela manifestação da sociedade, portanto, são "arranjos complexos, [...] que a ciência do direito deve estar apta a descrever, compreender e analisar, de modo a integrar à atividade política os valores e métodos próprios do universo jurídico". (BUCCI, 2006, p. 31).

Sendo que, de acordo com o Relatório de Desenvolvimento Humano - Brasil 2009/2010, (2010, p. 201) elaborado e realizado pelo Programa das Nações Unidas para o Desenvolvimento $^{2}$, uma nova concepção é dada às políticas públicas, pois intenciona trazer o cidadão para dentro desse processo, dando-lhe "um papel mais ativo na sua formulação", isto é, demostra um viés mais humanista já que o cidadão (e o grupo ao qual pertence) é sua razão de ser, pois as interdições postas ao indivíduo ou a um grupo específico, são fruto exatamente das relações sociais, como pontua Fernandes; Pinheiro, ([2000?], p. 02): [...] "Não é uma questão de assistência social, apesar de incluí-la, [...] é uma questão de cidadania e de direitos humanos".

Quanto às políticas sociais, pode-se afirmar que são uma subclasse das políticas públicas, estando, portanto, interligadas: “[...] toda política social é uma política pública, mas nem toda política pública é uma política social”, , ou seja, as políticas sociais são uma extensão das políticas públicas sendo ambas, portanto, o fruto das relações sociais e da intervenção do Estado sobre estas. Logo, são um meio dentre outros de se chegar a um fim específico. No entanto, para que tais políticas alcancem o fim esperado, importa que o Estado não se exima da responsabilidade pelos problemas persistentes, assim como a sociedade assuma uma participação consciente.

Partindo dessa conceituação, convém destacar a necessidade das mesmas frente a demanda étnico-racial que, na verdade, surge desde o sistema escravista e da implementação

\footnotetext{
${ }^{1}$ Do princípio da proporcionalidade: oferece uma relação ponderada entre meio e fim, de forma a minimizar potenciais danos. Da reserva do possível: permite ao Estado a realização de ações que estão dentro de sua capacidade econômica.

${ }^{2}$ Doravante, Pnud.

3 Rodrigues (2010, p.09) exemplifica descrevendo as políticas externa, econômica, administrativa, como políticas públicas importantes, mas não necessariamente ou diretamente sociais.
} 
Lei Áurea ${ }^{4}$, que, na verdade, não foi associada a nenhum processo fático de integração desses, o que culminou na impossibilidade de autossustentação e da ascensão social desses indivíduos. Desde o sistema escravista, então, tamanha displicência do Estado em não promover meios de acesso passou a produzir a exclusão que vivenciamos nos dias atuais, mesmo porque, o indivíduo que não é reconhecido como igual entre aqueles que determinam as características de pertença não será aceito naquele grupo, daí a razão da eugenia positiva, destacada entre o final do século XIX e os anos 1930 como forma de processamento da ideia de higienização da raça, tanto no sentido físico como no cognitivo, lançando mão do branqueamento gradativo através da miscigenação. Como exemplo dessa doutrina que pregava a inferioridade desses indivíduos, está o famoso escritor Monteiro Lobato ${ }^{5}$. Não por acaso, a noção de raça, ainda está vinculada às relações sociais e ao status hierárquico atribuído não só por quem a observa, mas também pelo próprio sujeito observado. Daí a variedade de termos previstos e observados pelos órgãos de pesquisa, como descrito pelo Instituto Brasileiro de Geografia e Estatística ${ }^{6}$, (2013, p.56),

[...] seja a miscigenação seja a política de branqueamento no Brasil, ambas possibilitaram a criação e a invenção de termos a fim de que diferentes segmentos ou grupos sociais pudessem ser "aceitos" e, assim, ascenderem no mercado matrimonial, no de trabalho, entre outros [...].

Por esse motivo, desde meados do século XIX o Estado proporciona uma política de imigração seletiva, dando privilégio aos imigrantes de origem europeia. Assim, ao mesclar brancos, negros (e indígenas), se obteria, com o passar das gerações, uma sociedade mais homogênea e mais branca, de acordo com os conceitos desenvolvidos por cientistas norteamericanos e ingleses, na qual cultivavam a ideia do "racismo científico" (SOUZA, 2012, p. $02)$.

Diante desse breve histórico, percebe-se que a demanda pela inclusão social dos afrodescendentes tornou-se cada vez mais emergente e, consequentemente, debatida em todos os seguimentos de estudo dos fenômenos sociais de modo geral, dentre esses, destaca-se o Direito e a Constituição Federal de 1988, como ensina, o professor e jurista Dalmo de Abreu Dallari ${ }^{7}$, em entrevista à Fundação Osvaldo Cruz (2008, http://www.epsjv.fiocruz.br):

Os direitos sociais ganharam peso grande e isso significou avanço extraordinário.

\footnotetext{
${ }_{5}^{4}$ Assinada pela Princesa Isabel, então regente, no dia 13 de maio de 1888.

${ }^{5}$ A expressão sanitarista de Lobato refletia o sentimento de alívio de grande parte da elite brasileiras, pois a higienia científica livraria o Brasil da eterna condenação à inferioridade. Vide (SOUZA, 2012, p. 05).

${ }^{6}$ Doravante denominado IBGE.

${ }^{7}$ Explica Dallari que a educação e trabalho ressaltados pela Constituição são um ponto de partida, pois ela própria prevê direitos sociais quando fala de direitos coletivos, de toda a sociedade.
} 
[...] partir de 1988, foram criados muitos instrumentos de ação social, inclusive dando responsabilidade a organizações públicas, como Ministério Público, pela garantia e efetivação dos direitos sociais.

Ainda, a Constituição de 1988, além de estabelecer essa série de direitos fundamentais, promove um processo de redemocratização, a partir de uma nova concepção de cidadania que tramita além do direito ao voto, ou seja, a cidadania como meio de concretização dos direitos fundamentais. Conforme instrui o professor José Afonso da Silva (1999, p.10), “A Constituição de 1988, que assume as feições de uma constituição dirigente, incorporou essa nova dimensão da cidadania [...] Cidadania está aqui num sentido mais amplo do que o de titular de direitos políticos".

Sob esse prisma, os indivíduos, ao partilharem de forma equânime os direitos e obrigações, estão na verdade promovendo a cidadania e, dessa maneira, contribuindo para a construção de uma coexistência minimamente sadia através da mobilização social e não somente pelo voto.

Como exemplo, está o Movimento Negro Unificado Contra a Discriminação Racial ${ }^{8}$, atuante desde 1978, que através da reunião de representantes das diversas entidades, procurava intimar a população negra a agir contra as manifestações racistas as quais eram sujeitados, inspirando os afrodescendentes à exteriorização de suas ideias ou transitarem para além do entorpecimento infligido através de ações de confronto à violência ${ }^{9}$, neste caso racial. É a partir da "organização desse tipo de movimento social" (SILVA, 2010, p. 02) que a população afro-brasileira se fez visível diante dos olhos da sociedade, tanto nacional quanto internacional.

Portanto, não se trata de mero favorecimento gratuito o emergir do negro brasileiro do oceano de dificuldades que se instalou no Brasil pós-abolição. Em verdade, tanto a viabilidade quanto a aplicabilidade das políticas sociais e ações afirmativas, são fruto do empenho da população afrodescendente e das entidades simpatizantes.

Não obstante, resta indubitável o fato de ser a Constituição Federal de 1988 um marco jurídico ímpar da história do país e, dentre tantos direitos e deveres expressos, percebese de forma nítida e peculiar, que ela evoca os direitos e garantias individuais e coletivos, como bem expressa no seu preâmbulo, “[...] o exercício dos direitos sociais e individuais, [...] a igualdade e a justiça [...] de uma sociedade fraterna, pluralista e sem preconceitos, fundada

\footnotetext{
${ }^{8}$ Doravante denominado MNU.

9 Violência, aqui, tem em vista qualquer ação ou omissão inspirada no constrangimento de outrem, independentemente de ser agressão física ou psicológica, de ordem racial, fisiológica, cultural ou social. Como exemplo, as agressões veladas, silenciosas ou "disfarçadas de brincadeira" em que o(s) opressor(es), numa postura dominante - e covarde - coage $(\mathrm{m})$ e segrega $(\mathrm{m})$ o oprimido, impedindo e/ou dificultando sua coexistência naquele núcleo. É uma das manifestações de bullying, inclusive, e está presente no seio familiar, no trabalho, nas escolas e, surpreendentemente, nas universidades.
} 
na harmonia social" $[\ldots]^{10}$.

A Constituição traz, portanto, uma abordagem mais significativa sobre os direitos sócias de acordo com dados colhidos por órgãos e institutos de pesquisa, observa-se que tal abordagem se fazia necessária, tanto é que, no seu Art. $3^{\circ}$ estão elencados como objetivos fundamentais, como a construção de uma sociedade livre, justa e solidária; a erradicação da pobreza e da marginalização e a redução das desigualdades sociais e regionais; a promoção do bem de todos, sem preconceitos de origem, raça, sexo, cor, idade e outras formas de discriminação.

Em referência à questão racial, a Constituição, além de tipificar como crime o racismo em solo brasileiro, também demonstra seu repúdio na esfera internacional: “Art. $4^{\circ}$ a República Federativa do Brasil rege-se nas suas relações internacionais pelos seguintes princípios: [...] VIII - repúdio ao terrorismo e ao racismo" [...], como também colabora, dentro das relações internacionais, com medidas de reconhecimento, desenvolvimento e inclusão dos afrodescendentes, estabelecendo uma relação de responsabilidade intergovernamental de combate às escaras socioculturais (e políticas) de cunho racial, como se vê na resolução 68/237 da $68^{\text {a }}$ Assembléia Geral das Nações Unidas que proclama A Década Internacional de Afrodescendentes ${ }^{11}$.

No entanto, muito embora tenha havido uma melhora significativa da demanda social dos afrodescendentes em virtude das políticas públicas e sociais como revelam os dados estatísticos resultantes de pesquisas dos órgãos como Instituto de Pesquisa Econômica Aplicada $^{12}$, tais melhorias alcançadas não podem ser caracterizadas como plenas, por certo, mas são inegáveis se consideradas a realidade dos jovens de hoje frente a realidade de seus ascendentes. É o que refere o Ipea ${ }^{13}$, no Boletim de Políticas Sociais - acompanhamento e análise $\mathrm{n}^{\mathbf{0}} 22$ ao retratar que a porcentagem do seguimento de nível superior setuplicou. Contudo, apesar do desenvolvimento educacional, os dados levantados no mesmo estudo supracitado, demonstram que, no seguimento do mercado de trabalho, as médias salariais entre brancos e negros deixam significativa diferença.

Retornando à abordagem jurídico-legal, a própria Constituição Federal, no seu Art. $1^{\text {o }}$, III, faz menção à "dignidade da pessoa humana" como um dos pilares do Estado Democrático de Direito: "Se é fundamento é porque se constitui num valor supremo [...] não é apenas um princípio da ordem jurídica, mas o é também da ordem política, social, econômica e cultural. Daí sua natureza de valor supremo, porque está na base de toda a vida nacional” [...]. (SILVA,

\footnotetext{
${ }^{10}$ Disponível em: https//www.planalto.gov.br/ccivil_03/constituicao/constituicaocompilado.htm.

${ }^{11}$ Vide: https://nacoesunidas.org/img/2014/10/N1362881_pt-br.pdf.

${ }^{12}$ Doravante Ipea.

${ }^{13}$ Vide: http://www.ipea.gov.br/igualdaderacial.
} 
1998, p. 91).

Logo, todos os direitos inerentes à integridade física, material e psicológica dos indivíduos são, fundamentalmente, uma responsabilidade do Estado e este, por sua vez, tem o dever-poder de proporcionar meios para viabilizar os direitos sociais e, consequentemente, a igualdade entre os indivíduos e/ou grupos, como se vê na tipificação do racismo (Art. $5^{\circ}$, XLII/CF) e da injúria (Art. 140/ CP).

Então, a legislação, muito embora incapaz de transformar a realidade preconceituosa e insistente nas mentes humanas, ao estabelecer proteção desse bem jurídico, repudiando e punindo a manifestações racistas e discriminatórias, estabelece um marco tanto nas relações sociais horizontais como verticais. Isso posto, o Direito, em resposta ao clamor dos afrodescendentes, constrói um novo olhar sobre a demanda étnico-racial bem como a permanência desse grupo na sociedade como sujeitos de direitos.

\section{Instrumentos legislativos para a implementação da política de inclusão do negro: a lei $12.711 / 2012$ e a lei $12.990 / 2014$}

Na lei $12.711 / 2012^{14}$, parte da reserva de $50 \%$ das matrículas por curso e turno nas universidades federais e institutos federais de educação, ciência e tecnologia, estão asseguradas aos indivíduos autodeclarados negros, pardos, indígenas, provenientes do ensino público, cuja condição socioeconômica está aquém das exigências reais preestabelecidas pela sociedade e em detrimento dela própria. Significa dizer, que no caso das cotas destinadas aos afrodescendentes, é imprescindível que haja a autodeclaração como negro ou pardo.

Consultando a lei supra, fica óbvio que essa porcentagem de $50 \%$ é fracionada entre os grupos étnico-raciais indígenas e negros, além de atender a população menos favorecida, o que, esclarece não pode ser considerado um benefício exclusivo dos afrodescendentes, ou seja, não é meramente étnico-racial. Quanto aos demais 50\% das vagas, estas destinam-se à ampla concorrência, conforme o Ministério da Educação ${ }^{15}$, sendo sua vigência de 10 (dez) anos.

Entende-se, em vista disso, que a lei 12.711/2012 traz um ponto de partida para efetiva equiparação material, trazendo ao cotista a chance de possuir pré-requisito básico para galgar cargos cuja a exigência mínima seja a graduação no ensino superior. Trata-se aqui, da implementação fática da democratização do ensino antes vista e sentida de maneira apenas simbólica.

No caso do Brasil, em virtude da problemática social, a acessibilidade ao ensino

\footnotetext{
${ }^{14}$ Vide: http://www.planalto.gov.br/ccivil_03/_ato2011-2014/2012/lei/112711.htm.

${ }^{15}$ Doravante MEC. Vide: http://portal.mec.gov.br.
} 
superior está vinculada à expansão para além dos grandes centros dispondo, também, mais vagas aos interessados; à democratização, de modo a converter a relação entre universidade e elite; à qualidade do ensino superior, intimamente relacionada ao corpo docente e a responsabilidade deste no processo de intermediação do conhecimento em virtude da dedicação envolvida na sistemática de ensino, a promovendo a qualificação de mestres e doutores.

Ainda, além da previsão na Constituição de 1988, a disponibilização do acesso ao ensino superior está recepcionada pelos órgãos internacionais vinculados aos direitos humanos, haja vista considerarem que a instrução deve promover (ou deveria promover) a compreensão e o respeito aos direitos humanos, como expressa a Declaração Universal Dos Direitos Humanos ${ }^{16}$.

Um ponto que convém destacar, ainda que brevemente, é o papel da universidade perante a sociedade. Eis, por exemplo, o compromisso da Universidade de Santa Cruz do Sul, UNISC ([2010?], http://www.unisc.br):

[...] A formação de profissionais habilitados e competentes é apenas uma parte do compromisso que assumimos. [...] Se um dos grandes desafios do ensino superior na atualidade é a formação integral do homem, outro diz respeito à inclusão de mais cidadãos no ensino superior [...].

Conforme a citação supra, depreende-se que a formação e a capacitação profissional não é e nem pode ser o único objetivo de qualquer instituição de ensino superior. Além desse objetivo, a universidade deve influenciar, de forma positiva, a formação do ser humano como parte ativa de um todo maior, proporcionando, na medida das possibilidades, acesso a todos os indivíduos e grupos. Assim, a flexibilização do acesso às universidades, portanto, permite que o Estado interfira nas relações entre os indivíduos de maneira que todos possam usufruir das benécias da ascenção social e, principalmente, sair do estado quo de marginalização.

Quanto à lei $12.990 / 2014^{17}$, no Artigo $1^{\circ}$ e parágrafos, nota-se que não há um percentual máximo preestabelecido e sim um percentual fixo de $20 \%$ do total das vagas as quais deverão ser informadas, expressamente, no edital.

Quando o número do total de vagas for igual ou superior a três, ajustando-se a fração para o número inteiro seguinte (maior que 0,5) ou anterior (até 0,5). Exemplificando, se a fração é de 3,5 vagas, se estenderá para 04 (quatro) vagas e se for 3,2 vagas, compreenderá 03 (três) vagas.

\footnotetext{
${ }^{16}$ Doravante DUDH. Vide: http://www.dudh.org.br/wp-content/uploads/2014/12/dudh.pdf.

${ }^{17}$ Vide: http://www.planalto.gov.br/ccivil_03/_Ato2011-2014/2014/Lei/L12990.htm.
}

Barbarói, Santa Cruz do Sul, Edição Especial n.47, p.<125-143>,jan./jun. 2016 
Quanto à sua aplicação, no que diz respeito ao âmbito da Administração Federal, ela não vincula Estados, Municípios, Judiciário e Legislativo Federal, mas apenas o Poder Executivo. No entanto, as cotas étnico-raciais para provimento de cargos efetivos também passam a compreender o âmbito do Conselho Nacional de Justiça por meio da Instrução Normativa $\mathrm{n}^{\circ} 63$ de 18 de março de $2015^{18}$.

Já o Artigo $2^{\circ}$ e parágrafo único/lei 12.990/2014 são, sem dúvida, é um ponto nevrálgico na lei. Ocorre que, para serem aptos às vagas/cotas previstas na lei, os candidatos deverão, impreterivelmente, se autodeclararem pretos ou pardos no ato da inscrição no concurso público, conforme o quesito cor ou raça utilizado pelo IBGE. Todavia, se, posteriormente, for averiguado que a autodeclaração, é falsa, o candidato será eliminado do concurso ou, se nomeado, poderá o candidato ter sua contratação anulada além sofrer outras possíveis sanções jurídicas.

Para entender melhor a classificação de cor, distingue-se, pelo menos, três meios de investigação étnico-racial: a autoatribuição, no qual o próprio indivíduo decide sua classificação, seja registrada por ele próprio em um formulário ou respondida ao entrevistador; a heteroatribuição de pertença, que define o grupo do sujeito; e a identificação de sua ascendência mediante técnicas e estudos biológicos, como a análise do DNA. "No sistema classificatório do IBGE, são empregados simultaneamente os métodos da autoatribuição e da heteroatribuição de pertença" (OSÓRIO, 2003, p.07).

Dessa forma, pergunta-se: qual o critério adotado por parte do órgão avaliador responsável para apurar a veracidade da autodeclaração? Eis aí uma desatenção do legislador.

Seguindo, no caso do Art. $3^{\circ}$ e parágrafos, ao candidato autodeclarado negro/pardo será permitido concorrer tanto às vagas cotadas como também às demais vagas, excepcionando, por óbvio, aquelas reservadas às pessoas com deficiência. Também, a vaga destinada à ampla concorrência que for preenchida por candidato negro/pardo, não será debitada do número de vagas reservadas. Todavia, caso o número de candidatos negros aprovados, dentro da cota, seja inferior às vagas, as que restarem serão integradas às vagas destinadas à ampla concorrência.

A lei em comento vigorará pelo prazo de 10 (dez) anos e o cumprimento dessa sistemática deverá ser avaliado anualmente pela SEPPIR.

Notadamente, portanto, mesmo aqueles que estiverem concorrendo às vagas disponíveis dentro do sistema de cotas, estarão sujeitos aos critérios de avaliação, ou seja, serão avaliados de acordo com o princípio meritocrático próprio dos concursos públicos. E, ao

\footnotetext{
${ }^{18}$ Vide: http://www.cnj.jus.br/atos-normativos?Documento=2130.
} 
falar-se em concursos públicos, fala-se em Direito Administrativo uma vez que este é o ramo do Direito que trata do interesse público por meio da Administração Pública.

Eis a conceituação do professor Celso Antônio Bandeira de Mello (2012, p. 48):

O Direito Público se ocupa de interesses da Sociedade como um todo, interesses públicos, cujo atendimento não é um problema pessoal de que os esteja a curar, mas um dever jurídico inescusável. Assim não há espaço para a autonomia da vontade, que é substituída pela ideia de função, de dever de atendimento do interesse público.

Portanto, a Lei 12.990/2014, ao prever as cotas étnico-raciais nos concursos públicos de nível superior, firmou sumariamente o vínculo com o Direito Administrativo visto ser este o ramo do Direito que estabelece regras balizadoras da Administração Pública, sem, por óbvio, se distanciar da ótica da Constituição Federal, que, aliás, a regulamenta.

Importa dizer que o Direito Administrativo se regulamenta através de princípios que sistematizam e unificam leis. Sendo assim, o instituto jurídico do concurso público é o procedimento administrativo previsto na Constituição Federal, ao qual o Estado lança mão para selecionar aqueles indivíduos que pretendem ocupar determinadas funções públicas. Importa afirmar que a instituição desse processo é determinada pela Constituição Federal, no seu capítulo VII, Art. $37^{19}$.

Entretanto, apesar de o Estado, por intermédio da Administração Pública, ter o poder de estabelecer os critérios de seleção para o provimento dessas vagas, não poderá exercê-lo sem a devida observação dos princípios norteadores do caput do Art. 37 da Constituição. Trata-se de uma dentre outras tantas limitações do Estado para que sejam reduzidos ao máximo os riscos de ilegitimidade nas contratações.

Derivado da ideia de República da Roma antiga, o Princípio Republicano está intrinsicamente ligado à constituição de que é o Brasil uma república estabelecida a partir dos preceitos democráticos. Sendo assim, vigora o sentido de público ou coletivo, e o dever de superar os interesses individuais, proporcionando ao Estado determinada estrutura, que não abrange só o direito ao voto, como também no direito isonômico de acesso aos cargos públicos, por meio do instituto do concurso público.

Também, o Princípio da Legalidade é fundamental ao regime jurídico administrativo, pois submete a Administração Pública à lei, ou seja, as ações da Administração Pública são decorrentes da permissão da lei. Diferentemente dos administrados que podem fazer qualquer coisa que não seja proibida pela lei, a Administração somente poderá fazer aquilo que a lei previamente autorizar.

Por sua vez, o Princípio da Impessoalidade impõe à Administração Pública o dever

${ }^{19}$ Vide: http://www.planalto.gov.br/ccivil_03/constituicao/constituicaocompilado.htm.

Barbarói, Santa Cruz do Sul, Edição Especial n.47, p.<125-143>,jan./jun. 2016 
de tratamento igualitário, sem discriminações, positivas ou negativas, pois se trata de uma finalidade pública prevista em lei, é o próprio instituto do concurso público como forma de ingresso nos cargos públicos um exemplo. Dessa forma, a Administração Pública, ao promover tais disputas, resguarda a isonomia entre os concorrentes, visando a finalidade pública legal.

No Princípio da Publicidade, a Administração Pública tem o dever de informar seus atos aos administrados, de forma pública e clara, abrangendo todos os âmbitos da atividade pública, além de promover a acesso às petições e certidões em repartições públicas ${ }^{20}$.

O Princípio da Eficiência, impõe à Administração Pública a obrigação de atuar com rapidez, perfeição e rendimento. Consubstanciado com o princípio da legalidade, obriga a Administração a perseguir os melhores resultados na relação custo versus benefício quando do atendimento das necessidades dos administrados.

Já o Princípio da Isonomia (ou Igualdade), está expresso no caput do artigo $5^{\circ}$ da Constituição Federal, e pode ser considerado um dos mais famosos fragmentos da Legislação Brasileira: "Todos são iguais perante a lei, sem distinção de qualquer natureza, [...]”. Todavia, apesar de seu tom heroico e nobre, para a Administração Pública, tal princípio não pode ser absoluto, assim como nenhum outro é. Significa dizer que não há de se falar em igualde entre os particulares e a Administração. Como é o caso do instituto do concurso público, já que visa tratar os concorrentes com igualdade, nesse sentido, entende-se, a exigência constitucional dos concursos públicos como forma de balizamento técnico ${ }^{21}$ dos administrados, por exemplo.

Por outro lado, há circunstâncias que permitem que a Administração Pública atue de forma desigual para promover a igualdade. É o que propõe as vagas para deficientes em concursos públicos e as cotas étnico-raciais, por exemplo, porém, investigando e avaliando a coerência entre o objeto e o tratamento diferenciado.

Um ponto que também merece destaque é a validade dos $\operatorname{concursos}^{22}$ : o prazo previsto no edital afeta diretamente o período de prorrogação. Assim, se o edital estabelece validade do concurso de 12 meses, por exemplo, a prorrogação será, obrigatoriamente de 12 meses. Também significa que não há impecílio na abertura de novo concurso, desde que seja respeitada a ordem de contratação dos candidatos já aprovados.

Quanto à reserva de cotas nos concursos públicos, a Constituição faz menção a esse tema no inciso VIII do Art. 37: [...] “a lei reservará percentual dos cargos e empregos públicos

\footnotetext{
${ }^{20}$ Vide incisos X, LX do Art. $5^{\circ}$ da Constituição Federal.

${ }^{21}$ Técnico, aqui, está relacionado ao conhecimento específico e necessário, próprio do cargo disposto no edital.

${ }^{22}$ Vide Art. 37, incisos III e IV da Constituição.
} 
para as pessoas portadoras de deficiência e definirá os critérios de sua admissão"; [...], sendo que a Lei $\mathrm{n}^{\circ}$ 8.112/1990 institui até 20\% das vagas para o público de pessoas com deficiência, não fazendo menção às cotas étnico-raciais, o que não obsta que sejam acrescidas outras cotas por meio de leis como a 12.990/2014.

\section{Os postulados teóricos e jurídicos das políticas públicas afirmativas de inclusão do negro no brasil e a (in)existência de bis in idem da lei 12.990/2014 frente a lei 12.711/2012}

Originárias da Índia, as políticas afirmativas buscavam atingir exatamente as desigualdades sociais derivadas da austera classificação de castas. Ao transportar tais políticas para o Brasil, mormente para as questões relacionadas às condições sociais dos afrodescendentes, resta inegável que as mesmas se faziam necessárias, entretanto, questionase se a política afirmativa implementada pela lei 12.990/2014 também se enquadraria nessa importância.

Os discursos que alimentavam a ideia da inferioridade de certas raças passaram a ser considerados politicamente incorretos especialmente depois da Segunda Guerra devido ao pensamento produzido pelo nazismo em relação aos judeus e aos sujeitos inaptos geneticamente. Partindo daí, surge um tipo de "movimento internacional de repúdio ao nazismo" (SILVA, 2007, p.30), o qual não foi suficiente para obstar as políticas racistas como o Apartheid, na África do Sul, e o Jim Crow, nos Estados Unidos, enquanto que, sobre o Brasil, pairava uma falsa imagem calcada no ideário da democracia racial.

Na década de 1980, observa-se o elo firmado entre a Constituição de 1988 e a abertura que ela estabelece para a criação e aplicação das ações afirmativas. Em sendo assim, a Constituição Federal vincula e impõe ao Estado a promoção de políticas e medidas sociais para a efetivação de direitos sociais por meio das ações afirmativas antes aplicados de maneira meramente principiológica ou formal.

Na seara étnico-racial, a SEPPIR ([2010?], http://www.seppir.gov.br), descreve: “ações afirmativas são políticas públicas feitas pelo governo ou pela iniciativa privada com o objetivo de corrigir desigualdades raciais presentes na sociedade, acumuladas ao longo de anos".

Muito embora o Estado esteja vinculado expressamente ao poder-dever de promover e garantir a equidade social por meio de políticas sociais, as ações afirmativas não são dever exclusivo desse, posto que as organizações sociais sem fins lucrativos e a iniciativa privada, por exemplo, também são personagens indispensáveis no processo que envolve as respectivas demandas, a elaboração e a aplicação das ações afirmativas, o que lhes confere o status de 
suporte complementar do Estado ${ }^{23}$.

Partindo do conceito de que é o ensino superior meio de promoção do desenvolvimento e consequente ascenção social, faz parecer lógica a existência de bis in idem entre as leis, 12.711/2012 e 12.990/2014, já que ambas visam a mesma ação. Exemplificando melhor, está a opinião do Sr. Dr. William Douglas, juiz federal (2014, http://williamdouglas.com.br), [...] "A cota nas universidades prepara para competir; nos concursos, elimina a competição onde ela é indispensável a bem do serviço público e dos seus destinatários".

No entanto, a posição do Conselho Federal da Ordem dos Advogados do Brasil (2016, http://www.stf.jus.br) coloca esse direito material em um nível mais elevado, sendo talvez o argumento mais contundente a esse respeito, de que a ação afirmativa em questão venha possibilitar uma cultura familiar de acesso. Imagina-se, portanto, que partindo de uma condição sociocultural de estabilidade in loco, torne verossímil o sentimento de pertença nas gerações vindouras. Tal estabilidade, num pensamento mais amplo, advém do pressuposto de que existe um equilíbrio de recursos entre os sujeitos. Dworkin (2005, p.160), explica o que seria esse equilíbrio de recursos: "A igualdade de recursos, por outro lado, oferece uma definição de igualdade distributiva imediata e obviamente sensível ao caráter especial e à importância da liberdade".

Para tanto, o Estado deve ser regulador dessa responsabilidade, de forma a conduzir tal comunidade de forma ponderada, equilibrando o possível às necessidades e redistribuindo recursos antes mal distribuídos.

Portanto, se levada, exclusivamente, em consideração o fato da lei 12.711/2012 promover o requisito mínimo necessário para lograr resultados nos concursos públicos, a aplicação da lei 12.990/2014 trará a ideia de que há uma relação de bis in idem entre as leis.

\section{Considerações finais}

A aplicação da lei 12.990/2014 trouxe inúmeros questionamentos, dentre estes, o questionamento deste estudo: os fundamentos da Política Pública de inclusão étnico-racial, através da reserva de cotas em concursos públicos de nível superior instituídas pela lei 12.990/2014, se sustentam diante do princípio da igualdade material, considerando que a política de inclusão social instaurada pela lei 12.711/2012 visa exatamente a promoção do requisito básico para o estabelecimento social do indivíduo na sociedade, a saber, as cotas

\footnotetext{
${ }^{23}$ Importa esclarecer que uma ação afirmativa não deve ser vista como um benefício exclusivo e/ou injusto. Ao contrário, a ação afirmativa só se faz necessária quando da percepção de um histórico de injustiças e direitos não certificados.
} 
para ingresso no ensino superior?

Para responder esse questionamento, foi exposto que, para que tais políticas venham lograr sucesso, importa que o Estado e a sociedade assumam seus lugares diante das obrigações e direitos pertinentes a cada um, sempre sob os ditames da Constituição Federal, que, aliás, teve papel importantíssimo no cenário nacional, promovendo não só a abertura para o diálogo sobre a demanda étnico-racial, como também o estabelecimento da proteção de um bem jurídico, repudiando e punindo a manifestações racistas e discriminatórias.

Ainda, foram pesquisados os argumentos de doutrinadores, pesquisadores e, de modo especial, os votos dos Ministros do Supremo Tribunal Federal que, inclusive, vieram corroborar a ideia de que as cotas étnico-raciais para ingresso nas universidades federais são o veículo para o estabelecimento do indivíduo como ser social. Assim sendo, ao analisar as leis 12.711/2012 e a lei 12.990/2014 em uníssono, e de forma exclusiva, confirma-se o entendimento de que há uma relação de bis in idem entre as mesmas, pois tornam-se redundantes quando do requisito específico para os concursos públicos de nível superior, ou seja, a graduação. Aqui, também, está refletido o Princípio da Igualde que rege, dentre outros, a Administração Pública e o instituto do Concurso Público.

Entretanto, para formação de um juízo fiel, deve-se dar atenção ao fato de que a lei 12.711/2012 não contempla exclusivamente os afrodescendentes. De fato, estes estão incluídos de forma específica numa parcela das cotas, mas não em sua totalidade. Acrescida a esse ponto, está a diferença socioeconômica, fruto de uma longa doutrina eugênica de inferiorização daqueles sujeitos descendentes da miscigenação de raças, de forma que a autoatribuição racial passou a ser sinônimo de classificação social, impedindo que aqueles sujeitos fossem incluídos na sociedade de consumo e produtividade sendo considerados como desiguais ou até inferiores. Assim, firmou-se ideia de a cor e o fenótipo serem determinadores sociais.

Ainda, deve-se levar em conta que o Estado Brasileiro administra suas relações internacionais por meio de princípios, dentre os quais o repúdio ao racismo, que o vincula à responsabilidade intergovernamental de combate à toda manifestação de caráter racista assim como na implementação de ações que permitam a ascenção social dos afrodescendentes e a efetivação da dignidade destes enquanto sujeitos de direitos, incluindo aqui a dignidade das gerações vindouras de serem parte de um núcleo familiar no qual o senso de pertença lhes serão comuns. Neste último caso, nota-se a mais convincente das alegações sobre a importância da lei 12.990/2014: a possibilidade da construção de uma cultura de pertencimento, incomum até então.

Por essas razões, depreende-se que, apesar da aparente redundância da razão de ser 
das leis 12.711/2012 e 12.990/2014 se comparadas somente entre si, por força de um bem maior que é a viabilização do equilíbrio social, somado ao interesse de promoção do senso de pertença das gerações vindouras, as cotas étnico-raciais para provimento de vagas por meio dos concursos públicos são aceitáveis e se sustentam perante o princípio da igualdade material.

\title{
THE POLICY OF ETHNIC-RACIAL QUOTAS FOR PUBLIC COMPETITIONS OF HIGHER EDUCATION LEVEL
}

\begin{abstract}
The problematic situation that prompted this research is whether the foundations of public policies of ethnic-racial inclusion, by reserving quotas for those who take the civil servants exams of higher education levels, introduced by the Law 12.990/2014, which are supported on the principle of material equality, - taking into consideration the already existing inclusion policy for higher education in public universities for this group? To answer this question, the approach method used was the hypothetical-deductive one, considering the fact that, from the problem, some hypotheses emerged and they can be argued, which will be refuted or confirmed along the research. As for the research technique, the bibliography checking was used, as well as periodicals and jurisprudential collections. Thus, starting from the assumption that the existing Public Policy on ethnic-racial quotas for inclusion on these exams was implemented by the Law 12,711/2012, that enables the minimum requirement for those candidates willing to fill the number of vacancies made available by the Public Administration, it can be said that there is a bis in idem relationship concerning to the laws under discussion. However, despite this fact, it remains understandable and acceptable the law enforcement 12.990/2014 due to the obligation of the State, including the international aspect, to promote the fullness of material equality, as well as the argument of the Bar Association of Brazil and the promotion of socio-cultural stability in loco, providing a sense of belonging for those generations yet to come.
\end{abstract}

Keywords: Civil servant examinations; quotas; material equality; public policy.

\section{Referências bibliográficas}

BRASIL. Constituição Federal de 1988. Constituição da República Federativa do Brasil. Brasília, DF: Senado Federal, 1988. Disponível em: <http://www.planalto. gov.br/ccivil_03/constituicao/constituicaocompilado.htm>. Acesso em: 06 fev. 2015.

Código Penal Brasileiro. Rio de Janeiro, RJ: Presidência da República, 1940.

Disponível em: <http://www.planalto.gov.br/ccivil_03/decreto-lei/Del2848 compilado.htm>. Acesso em: 28 abr. 2016.

Decreto no 4.228 de 2002. Brasília, DF: 13 de maio de 2002. Disponível em: <http://www.planalto.gov.br/ccivil_03/decreto/2002/D4228.htm>. Acesso em: 24 maio 2016.

Instrução Normativa n ${ }^{\circ} 63$ de 18 de março de 2015. Brasília, DF: 18 de março de

2015. Disponível em: <http://www.cnj.jus.br/atos-normativos?Documento $=2130>$. Acesso em: 17 jun. 2016 . 
. Lei ${ }^{\circ}$ 8.112, de 11 de dezembro de 1990. Brasília, DF: 11 de dezembro de 1990. Disponível em: <http://www.planalto.gov.br/ccivil_03/leis/L8112cons.htm>. Acesso em: 08 jun. 2016.

Lei no 9.784, de 29 de janeiro de 1999. Brasília, DF: 29 de janeiro de 1999.

Disponível em: <http://www.planalto.gov.br/ccivil_03/LEIS/L9784.htm>. Acesso em: 12 out. 2015.

. Lei $\mathrm{n}^{\mathrm{o}}$ 12.711, de 29 de agosto de 2012. Brasília, DF: 29 de agosto de 2012.

Disponível em: <http://www.planalto.gov.br/ccivil_03/_ato2011-2014/2012/lei/112711. htm>. Acesso em: 07 maio 2016.

Lei no 12.990, de 09 de junho de 2014. Brasília, DF: 09 de junho de 2014.

Disponível em: <http://www.planalto.gov.br/ccivil_03/_Ato2011-014/2014/Lei/L12990.

htm>. Acesso em: 06 fev. 2015.

Ministério da Educação. Disponível em: <http://etnicoracial.mec.gov.br/ acoes-afirmativas-cotas-prouni>. Acesso em: 31 mar. 2016.

Ministério da Educação. Disponível em: <http://portal.mec.gov.br/index. php?option=com_content\&view=article\&id=20000\&Itemid=1276>. Acesso em: 31 mar. 2016.

Ministério da Educação. A democratização e expansão da educação superior no país 2003 - 2014. Disponível em: <http://portal.mec.gov.br/index.php? option=com_docman $\&$ view=download $\&$ alias=16762-balanco-social-sesu-20032014\&Itemid=30192>. Acesso em 10 maio 2016.

. Ministério da Educação. Disponível em: <http://portal.mec.gov.br/sesu/ arquivos/pdf/livrosesu.pdf>. Acesso em: 25 maio 2016.

Secretaria de Políticas de Promoção da Igualdade Racial. O que são Ações Afirmativas. Disponível em: <http://www.seppir.gov.br/assuntos/o-que-sao-acoesafirmativas>. Acesso em:19 maio 2016.

Supremo Tribunal Federal. Inteiro teor da Arguição de Descumprimento de Preceito Fundamental 186/2012 - DF. Disponível em: <http://www.stf.jus.br/portal/ inteiroTeor/pesquisarInteiroTeor.asp\#resultado>. Acesso em: 17 maio 2016.

Supremo Tribunal Federal. OAB pede declaração de constitucionalidade da Lei de Cotas. Disponível em: <http://www.stf.jus.br/portal/cms/verNoticiaDetalhe. asp?idConteudo=308736\&caixaBusca=N>. Acesso em: 19 maio 2016.

Supremo Tribunal Federal. Súmula 685. Disponível em: <http://www.stf.jus. $\mathrm{br} /$ portal/cms/verTexto.asp?servico=jurisprudenciaSumula\&pagina=sumula_601 _700>. Acesso em: 17 maio 2016.

BUENO, Marisa Fernanda da Silva. A construção do pensamento político-educacional sobre o programa de cotas étnico-raciais nas universidades federais brasileiras. Dissertação (Programa de Pós-Graduação em Desenvolvimento Regional - Mestrado) Universidade de Santa Cruz do Sul, Santa Cruz do Sul, 2015. 
DALLARI, Dalmo de Abreu. Entrevista de Dalmo de Abreu Dallari. Disponível em: <http://www.epsjv.fiocruz.br/upload/em\%20debate\%2020\%20anos\%20sus/Microsoft_WordDalmo_de_Abreu_Dallari.pdf>.Acesso em: 29 abr. 2016.

DI PIETRO, Maria Sylvia Zanella. Direito administrativo. 27. ed. São Paulo: Atlas, 2014.

DWORKIN, Ronald. A virtude soberana: a teoria e a prática da igualdade. São Paulo: Martins Fontes, 2005.

FERNANDES, I.; PINHEIRO, H.C.L. Acessibilidade universal e as políticas públicas. Disponível em: <http://ebooks.pucrs.br/edipucrs/anais/sipinf/edicoes/I/14.pdf〉. Acesso em: 27 abr. 2016.

FILHO, José dos Santos Carvalho. Manual de direito administrativo. 27. ed. São Paulo: Atlas, 2014.

IBGE. Instituto Brasileiro de Geografia e Estatística. Disponível em: <http://www. ibge.gov.br>. Acesso em: 09 abr. 2016.

. Instituto Brasileiro de Geografia e Estatística. Características étnico-raciais da população classificações e identidades. Disponível em: < http://loja.ibge.gov.br/ caracteristicas-etnico-raciais-da-populac-o-classificacoes-e-identidades.html . Acesso em: 09 abr. 2016.

IPEA. Instituto de Pesquisa Econômica Aplicada. Disponível em: <http://www.ipea. gov.br/igualdaderacial/index.php?option=com_content\&view=article\&id=711>. Acesso em: 10 abr. 2016.

LEWANDOWSKI, Enrique Ricardo. Reflexões em torno do princípio republicano. Revista da Faculdade de Direito da Universidade de São Paulo, 2005, v. 100 p. 189 -200.

Disponível em: <http://www.revistas.usp.br/rfdusp/article/viewFile/67670/ 70278>. Acesso em: 27 maio 2016.

LOPES, José Reinaldo de Lima. O direito na história: lições introdutórias. 4. ed. São Paulo: Atlas, 2012.

MELLO, Celso Antônio Bandeira de. Curso de direito administrativo. 17. ed. São Paulo: Malheiros, 2004.

MELLO, Marco Aurélio. Óptica constitucional - A Igualdade e as Ações Afirmativas. Revista Academia Paulista de Magistratura, São Paulo, copyright 2014 - APM - Academia Paulista de Magistrados, $\mathrm{n}^{\circ}$ 01. Disponível em: <http://www.apmbr.com.br /editor/assets/pdf/revista-apm-nr1.pdf>. Acesso em: 26 maio 2016.

ONUBR. Organização das Nações Unidas no Brasil. Declaração do Direitos Humanos. Disponível em: <http://www.dudh.org.br/wp-content/uploads/2014/12/ dudh.pdf>. Acesso em: 10 maio 2016.

Organização da Nações Unidas no Brasil. Resolução 68/237, item 67, agenda b. Nova York, 2013. Disponível em: <https://nacoesunidas.org/img/2014/10/ N1362881_pt-br.pdf>. Acesso em: 26 maio 2016. 
OSÓRIO, Rafael Guerreiro. Texto para discussão $n^{\circ}$ 996: O sistema classificatório de "cor ou raça” do IBGE. Brasília, novembro de 2003. Disponível em: <http://www.

ipea.gov.br/portal/images/stories/PDFs/TDs/td_0996.pdf>. Acesso em: 13 out. 2015.

PNUD. Programa das Nações Unidas para o Desenvolvimento. Valores e desenvolvimento humano 2009/2010. Brasília, 2010. Disponível em: <http://www.pnud.org.br/ HDR/arquivos/rdh_brasil_2009_2010.pdf>. Acesso em: 27 abr. 2016.

PORTAL DA IGUALDADE. O que são ações afirmativas? Disponível em: <Http:// www.portaldaigualdade.gov.br/assuntos/o-que-sao-acoes-firmativas\#wrapper>. Acesso em: 22 ago. 2015.

RODRIGUES, Marta Maria Assumpção. Políticas públicas. São Paulo: Publifolha, 2010.

SANTOS, William Douglas Resinente dos. A propósito das cotas nos concursos públi-cos. Disponível em: <http://williamdouglas.com.br/a-proposito-das-cotas-nos-concursospublicos>. Acesso em: 28 maio 2016.

SCHWARCZ, Lilia Moritz. O espetáculo das raças. São Paulo: Companhia das Letras, 1993.

Espetáculo da miscigenação. Estudos avançados, v. 8, n.20, p. 137-152, 1994.

Disponível em: <http://www.scielo.br/pdf/ea/v8n20/v8n20a17.pdf>. Acesso em 03 set. 2014.

SILVA, José Afonso da. Acesso à justiça e cidadania. Revista de Direito Administrativo, Rio de Janeiro, 1999, v. 216. Disponível em: <http://bibliotecadigital.fgv.br/ojs/ index.php/rda/article/view/47351/45365>. Acesso em: 07 maio 2016.

A dignidade da pessoa humana como valor supremo da democracia. Revis-ta de Direito Administrativo, Rio de Janeiro, 1998, v. 212. Disponível em: <http:// bibliotecadigital.fgv.br/ojs/index.php/rda/article/view/47169/45637>. Acesso em 07 maio 2016.

SILVA, Mozart Linhares da. Biopolítica, raça e nação no Brasil (1870-1945). Cader-nos IHU ideias, São Leopoldo, 2015, ano 13, nº 235, v.13.

Ciência, raça e racismo na modernidade. Santa Cruz do Sul: EDUNISC, 2009.

Considerações sobre o dilema entre cor/raça/mestiçagem e ações afirmativas no Brasil. Reflexão \& Ação, Santa Cruz do Sul, 2010, v. 18, p. 8-29.

. Michel Foucault e a genealogia da exclusão/inclusão: o caso da prisão na modernidade. Revista de estudos criminais, 2005, ano V, n 17, p. 43-44.

Miscigenação e Biopolítica no Brasil. Revista Brasileira de História \& Ciências Sociais. 2012, v. 4, $\mathrm{n}^{\circ} 8$.

SOUZA, Vanderlei Sebastião de. As ideias eugênicas no Brasil: ciência, raça e projeto nacional no entre-guerras. Revista Eletrônica História em Reflexão, Dourados, v.6 n. 11, jan.jun. 2012. Disponível em: <http://www.periodicos.ufgd.

edu.br/index.php/historiaemreflexao/article/viewFile/1877/1041>. Acesso em 08 set. 2014.

STEPAN, Nancy Leys. A hora da eugenia: Raça, gênero e nação na América Latina. Rio de 
Janeiro: FIOCRUZ, 2005.

UNISC. Universidade de Santa Cruz do Sul. Apresentação: O humanismo, a democracia e o ideal comunitário são marcas da UNISC. Disponível em: <ttp://www.unisc. br/portal/pt/a-unisc/a-universidade/apresentacao.html>. Acesso em: 16.maio 2016.

\section{Sobre a autora:}

Grace Vieira Martinez Pena é Bacharelanda do Curso de Direito da Universidade de Santa Cruz do Sul - UNISC - 2016. Endereço Eletrônico: gvmpena@yahoo.com.br

Denise Bittencourt Friedrich é Graduada em Direito pela Universidade de Santa Cruz do Sul (2002); Especialista em Direito Constitucional - ênfase em Direito Municipal pela Universidade Luterana do Brasil (2005); Mestre em Direito - Políticas Públicas de Inclusão Social- pela Universidade de Santa Cruz do Sul. (2007). Doutora em Direito pela Universidade de Santa Cruz do Sul - UNISC - (2014) Docente da Universidade de Santa Cruz do Sul - UNISC- e professora permanente do PPGD desta universidade. Endereço Eletrônico: d-friedrich@hotmail.com

Mozart Linhares da Silva é Graduado em História pela Pontifícia Universidade Católica do Rio Grande do Sul (1993), mestrado (1996) e doutorado (2001) em História pela Pontifícia Universidade Católica do Rio Grande do Sul, com extensão da Universidade de Coimbra, e pós-doutorado em Educação, ênfase em Estudos Culturais e Estudos Foucaultianos, pela UFRGS (2014). É adjunto III da Universidade de Santa Cruz do Sul, onde atua desde 1998. Tem experiência nas áreas de História, com ênfase em História das Idéias e Educação, atuando principalmente nos seguintes temas: Estudos Culturais e educação, Estudos Foucaultianos, História da Educação e Etnicidade e Educação. Líder do Grupo de Pesquisa CNPq Educação e Estudos Culturais. Endereço Eletrônico: mozartt@terra.com.br 